dren's intellectual development. Children test hypotheses about the physical and social world around them from the time they are born, and form new hypotheses when the old ones prove unsatisfactory. They do so exactly like scientists, according to Gopnik and Meltzoff.

In particular, the authors claim that the hypotheses children entertain are always falsifiable and that children treat them as such. Like good scientists, children recognize when one of their ideas has not worked out and they look for a new and better one.

And the endpoint? Well, all that happens is that after a while people get tired of the whole process and are content to stick with the hypotheses they happen to have reached by then. So the authors contend that adulthood is the end, not the beginning, of scientific reasoning for most people.

This argument goes flat against the idea of development as a series of changes from an immature to a more-or-less complete system. On the contrary, the authors argue that the child's intellectual machinery undergoes no change at all. The process of testing and forming new hypotheses is the same in adolescence as in the first few days of life.

The child's hypotheses get closer to the truth as time goes by and the result is that the child's knowledge about the world keeps on growing. But the intellectual machinery that leads to this growth is always the same, until it burns out in early adulthood.

The book deals mainly with children up to the age of two years and is mostly concerned with their understanding of physical objects and social interactions. There are sections on children's success in solving simple means-ends problems (such as getting a necklace into a jar), on the way in which they categorize objects and on the first stages of language acquisition.

Much of the argument is based on a reanalysis of well-known phenomena. For example, the authors dwell at length on the familiar observation (originally Piaget's) of the 'A not B' error: babies who see an adult hiding an object in one place (A) and then later in another place (B) will go on looking for the object at $A$ even when they have just closely watched the adult put it in B.

According to the authors, babies make this particular mistake because they have formed a hypothesis that "the object will be where it appeared before" and arrive at this hypothesis on the basis of experiences such as dropping a toy out of their cot and not seeing it again until it has been tidied up and put back where it was originally.

This particular argument is typical of the book. It is ingenious and amusing and it could be right. But the authors offer no evidence for it. They do throw doubt (quite rightly, in my view) on one competing theory - that the error is due to the limitations in the children's ability to remember the sequence of events. Yet they fail to test, or even consider how to test, their own hypothesis even though it is, it seems to me, eminently testable.

Given the authors' willingness to offer a new view of babies' intellectual achievements, their unwillingness to find a way of testing it is ironic — after all, the book's main purpose is to persuade us how well young children set about testing their own hypotheses. The nearest they come to offering a direct test is in their account at the end of the book of their own work on language acquisition and on children's success in solving means-ends problems, in categorization tasks where they have to work out what has happened to an object they can no longer see ("object permanence").

Their research reveals specificity in the connections between different aspects of language acquisition and children's performance in different cognitive tasks. For example, they have shown a strong relationship between children's use of words denoting success and failure and their abili- ty to solve means-ends problems and a similarly close connection between their learning of words to do with appearance and disappearance and their success in object-permanence problems. No such connection was found across these two categories, however.

This is good research with genuinely interesting results, but it does not get near to establishing that these changes happen because babies test and abandon unsuccessful hypotheses and then form new ones.

We are left with a lively and entertaining book that will make us think again about children's intellectual development but will in the end convince no one. The authors will have to find some direct way of investigating how children form and abandon hypotheses if they want their fellow developmental psychologists to give up on one view and to espouse a completely different one.

Peter Bryant is in the Department of Experimental Psychology, University of Oxford, South Parks Road, Oxford OX1 3UD, UK.

\title{
At a glance
}

Excellent $t+x+$ Good $x+x$ Fair $x+$ Poor

\section{Quantum Mechanics in Chemistry}

by Jack Simons and Jeff Nichols

Oxford University Press: 1977. Pp. 612.

$£ 48.50, \$ 70$

Good books on quantum mechanics in chemistry are always welcome. This book contains the standard wavefunction and orbital material with many examples. Angular momentum theory, determinants, configuration interaction, molecular rotation and vibration, and time-dependent processes (including a good introduction to scattering) are all clearly introduced. There is a section on quantitative methods, introducing the Hartree-Fock method and basis sets. The authors' expertise in more advanced methodology such as MCSCF and response theories appears in the last chapter. There is also a 125-page appendix.

This well-written text provides a good basis to standard quantum chemistry. But I have an important criticism. In the past four years, density functional theory has 'taken over' computational chemistry. Here it is given four pages only, written from a historical, out-of-date perspective. The theory should be given prominence in modern texts on quantum chemistry.

Nicholas C. Handy Department of Chemistry, University of Cambridge, Cambridge CB2 1EW, UK.

\begin{tabular}{lc}
\hline Range & $\star \star \star$ \\
\hline Depth & $\star \star \star$ \\
\hline Accuracy & $\star \star \star$ \\
\hline Up-to-dateness & $\star \star$ \\
\hline Accessibility & $\star \star \star$ \\
\hline Style & $\star \star \star \star$
\end{tabular}

Vertebrate Palaeontology, second edition

by Michael J. Benton

Chapman and Hall: 1997. Pp. 452. £75, \$110

(hbk); $£ 24.99, \$ 50$ (pbk)

Aiming to outline more than 500 taxonomic groups of living and fossil vertebrates in fewer than 400 pages of well-illustrated text is ambitious. Michael J. Benton has successfully updated and expanded the first edition (1990) to make it a more thorough introduction to the topic. For example, the new developments in the understanding of tetrapod and avian evolution are here, along with new illustrations, references from 1996, detailed discussion 'boxes' on topics such as the "birds of Las Hoyas" and "Permian burrowing dicynodonts of the Karoo", and new cladograms.

Sections on preservation, ecology, biomechanics, plate tectonics and theories of extinction are all necessary to help explain and interpret the peculiarly biased nature of the fossil record, especially to biologists without a palaeontological background. But these days many, if not most, students of vertebrate fossils have little idea about basic vertebrate zoology. They will need to supplement this book with a standard text on vertebrate zoology.

Douglas Palmer 31 Mawson Road, Cambridge CB1 2DZ, UK.

\begin{tabular}{lc}
\hline Range & $\star \star \star \star$ \\
\hline Depth & $\star \star \star$ \\
\hline Accuracy & $\star \star \star \star$ \\
\hline Up-to-dateness & $\star \star \star \star$ \\
\hline Accessibility & $\star \star \star \star$ \\
\hline Style & $\star \star \star \star$ \\
\hline
\end{tabular}

